\title{
Dienogest increases the progesterone receptor isoform $B / A$ ratio in patients with ovarian endometriosis
}

Atsushi Hayashi, Akiko Tanabe*, Sachiko Kawabe, Mika Hayashi, Hiroko Yuguchi, Yoshiki Yamashita, Kiyoji Okuda and Masahide Ohmichi

\begin{abstract}
Background: The resistance of endometriotic tissue to progesterone can be explained by alterations in the distribution of progesterone receptor (PR) and estrogen receptor (ER) isoforms. The aims of this study were to examine the expressions of PR-A, PR-B, ERa and ER $\beta$ in endometrioma and assess whether these expressions are affected by dienogest or leuprolide acetate $(L A)$ treatment.

Methods: We enrolled 60 females, including 43 patients with endometriosis (14 who received no medical treatment, 13 who received dienogest and 16 who received LA before undergoing laparoscopic surgery) and 17 patients with leiomyoma. The expression levels of PR and ER isoforms in eutopic and ectopic endometrium were assayed with quantitative real-time PCR, and confirmed with immunohistochemistry.

Results: A decreased PR-B/PR-A ratio and an increased ERB/ERa ratio were demonstrated in ectopic endometrium derived from females with endometriosis compared with the ratios observed in eutopic endometrium obtained from females without endometriosis. Although LA treatment did not affect the PR-B/PR-A and ERB/ERa ratios, dienogest treatment increased the PR-B/PR-A ratio and decreased the ERB/ERa ratio in patients with endometriomas.
\end{abstract}

Conclusions: Dienogest may improve progesterone resistance in endometriotic tissue by increasing the relative expressions of PR-B and PR-A, and decreasing the relative expressions of ERB and ERa.

Keywords: Dienogest, Progesterone receptor isoforms, Estrogen receptor isoforms, Ovarian endometriosis, Progesterone resistance

\section{Background}

Endometriosis is an estrogen-dependent inflammatory disease that affects $6-10 \%$ of females of reproductive age [1]. It is characterized by the presence of endometrium-like tissue outside the uterine cavity, primarily on the ovaries, and represents one of the most common causes of chronic pelvic pain, dysmenorrhea and infertility [2]. The main aims of treatment are to alleviate pain and other symptoms, reduce the size of the endometriotic lesions and improve the quality of life of affected individuals. Nonsteroidal anti-inflammatory drugs are frequently used by patients with endometriosis in

\footnotetext{
*Correspondence: gyn074@poh.osaka-med.ac.jp

Department of Obstetrics and Gynecology, Osaka Medical College, 2-7 Daigaku-machi, Takatsuki city, Osaka 569-8686, Japan
}

an attempt to relieve pelvic pain, although clinical trial evidence to support the efficacy of these agents in endometriotic patients is lacking [3]. Gonadotropin-releasing hormone $(\mathrm{GnRH})$ agonists are an established therapy for endometriosis. Although $\mathrm{GnRH}$ agonists provide effective pain relief and reduce the progression of endometriotic implants [4], the hypoestrogenic state they induce is associated with negative effects such as accelerated bone mineral density loss, hot flashes and vaginal dryness [5]. Oral contraceptives (OCs) are widely used to treat the symptoms of endometriosis, although they are not approved for this indication in the majority of countries due to the lack of supportive trial evidence [6]. Progestins have long been used for the treatment of endometriosis to relieve pain by suppressing ovarian estrogen biosynthesis, in turn, suppressing growth and

\section{Biomed Central}


inflammation [7]. Unfortunately, the relief of pain appears to be relatively short-term [8], and approximately $9 \%$ of females with endometriosis simply do not respond to progestin therapy due to unknown reasons [9]. In fact, a general tendency for relative progesterone resistance within the eutopic and ectopic endometrium of females with endometriosis is welldocumented $[1,10]$.

Recently, two major progesterone receptor (PR) isoforms were identified, namely PR-A and PR-B (11). PR-A is a $94-\mathrm{kDa}$ protein, whereas $\mathrm{PR}-\mathrm{B}$ is a $114-\mathrm{kDa}$ protein that contains an additional NH2-terminal stretch of approximately 165 amino acids containing a region encoding a transactivation function. These isoforms may arise as a result of either initiation of translation from alternative sites in the same messenger RNA (mRNA) [11] or by transcription from alternative promoters [12]. Although the exact functions of each of these isoforms remain unclear, there is increasing evidence that they are functionally different $[12,13]$. PR-B tends to be a stronger activator of progesterone target genes, whereas PR-A has been shown to act as a dominant repressor of PR-B $[14,15]$.

Endometriosis is associated with a reduced response to progesterone in both eutopic and ectopic endometrium. According to recent reports, the resistance of endometriotic tissue to progesterone, evident in both laboratory and clinical observations, can be explained by alterations in the distribution of ER and PR isoforms and dysregulation of progesterone target genes [10,16-18]. Because the effects of progesterone on target genes are conferred primarily by PR-B in the endometrium [19], the presence of the inhibitor isoform-A and the absence of the stimulatory isoform-B provide a possible explanation for progesterone resistance in endometriotic implants. In fact, a decreased PR-B/PR-A ratio has been demonstrated in ectopic tissue [20,21], and recent reports suggest that the tendency toward progesterone resistance in patients with endometriosis is likely the result of the promotion of hypermethylation of PR-B, which renders PR-B either silenced or downregulated [21]. Moreover, a number of investigators have reported markedly elevated levels of $\mathrm{ER} \beta$ and lower levels of ER $\alpha$ in human endometriotic tissues and primary stromal cells compared with that observed in eutopic endometrial tissues and cells $[16,22,23]$. ER $\beta$, acting as an ER $\alpha$ suppressor, might contribute to the decreased PR levels and progesterone resistance observed in patients with endometriosis [24].

Dienogest (17a-cyanomethyl-17b-hydroxyestra-4,9-dien3-one) is an oral progestin that has been systematically investigated for the treatment of endometriosis in doseranging [25], placebo-controlled [26,27], active comparatorcontrolled [28,29] and long-term trials [30] conducted in Europe and Japan. The main anti-endometriotic effect of dienogest has been suggested to be attributable to central inhibition of ovulation. Furthermore, direct antiproliferative effects of dienogest have been demonstrated in human eutopic endometrial stromal cells [31]. Recent studies demonstrate that dienogest inhibits the proliferation of endometriotic stromal cells [32], prostaglandin E2 production and the aromatase mRNA expression of the endometrial epithelial cell line [33]. However, there is no evidence regarding whether dienogest improves progesterone resistance in patients with endometriosis. In the present study, therefore, we examined the effects of dienogest on alterations in the ratios of PR-B to PR-A and ER $\beta$ to ER $\alpha$ in ectopic endometrial tissue obtained from endometriotic females.

\section{Methods}

\section{Patients and tissue collection}

Sixty patients treated between January 2002 and July 2010 were included in this study. All patients were under treatment at the department of obstetrics and gynecology of Osaka Medical College. This was a retrospective cross-sectional case-controlled study of human tissue samples approved by the Institutional Review Board of Osaka Medical College. Written informed consent was obtained from all patients participating in the study.

The inclusion criteria were: older than 20 years age of and no more than 50 years of age at the time of the surgical procedure, the presence of regular menstrual cycles (24-35 days of interval) with the exception of those treated with leuprolide acetate (Leuplin; Takeda pharmaceutical, Osaka, Japan) for endometriosis, the absence of any evidence of past or recent pelvic inflammatory disease and no history of any hormonal treatment for at least 12 months at baseline. Trans-vaginal ultrasonography was performed for all patients, and showed mainly hypoechoic cystic masses in the ovaries, and the presence of ovarian endometriomas were confirmed before surgery by magnetic resonance imaging (MRI), which showed high-intensity areas on both T1- and T2weighted images. The serum level of CA125 was also measured before surgery using automated assays on a Roche Modular E170 instrument (Roche, Vilvoorde, Belgium) at the central laboratories of Osaka Medical College. Tissue specimens were obtained from females $(n=43)$ treated with dienogest at a dose of $2 \mathrm{mg}$ (dienogest group; $n=13$ ) for three to five months or leuprolide acetate (LA) at a dose of $3.75 \mathrm{mg}$ (LA group; $\mathrm{n}=16$ ) administered before surgery. Simultaneous sampling of ovarian endometrioma capsules was performed during laparoscopic surgery for indications of adnexal masses consistent with ovarian endometrioma. The stage of endometriosis in each case was documented according to the revised American Society of Reproductive Medicine Criteria (r-AFS stage) [34]. The diagnosis of endometriosis was confirmed histologically. Normal endometrial tissues $(n=17)$ were obtained using biopsies 
during the proliferative phase of the menstrual cycle in patients undergoing hysterectomy for uterine fibroids.

The samples obtained from the ectopic and eutopic endometrium were immediately frozen in liquid nitrogen for further RT-PCR analyses, fixed in 10\% formaldehyde and then routinely processed for paraffin embedding for a histological analysis.

\section{OneStep real-time polymerase chain reaction}

Total RNA was obtained using the RNeasy Mini kit (Qiagen, Germantown MD), and $2 \mu \mathrm{g}$ were reverse transcribed with Superscript II RNase H-reverse transcriptase (Invitrogen) using random primers according to the manufacturer's instructions. Oligonucleotide primers for TaqMan probes were designed with the use of Primer Express (version 1.0; Perkin-Elmer Applied Biosystems, Tokyo, Japan) from the GeneBank database. Human GAPDH was purchased from Perkin-Elmer Applied Biosystems and used as an internal standard. The primers used in this study are shown in Table 1. The first primer set, termed PR-B, was designed to amplify sequences specific for PR-B (upstream of the second AUG translation initiation site), whereas the second primer set, total $\mathrm{PR}$, was designed to amplify sequences downstream of the second AUG translation initiation site. None of these primer sets corresponded to sequences in any of the other steroid hormone receptors. The cDNA template was amplified using quantitative real-time polymerase chain reaction (qRT-PCR), as previously described [35]. Briefly, the cDNA template was amplified in a $20 \mu \mathrm{L}$ reaction containing $1 \mathrm{x}$ TaqMan Universal PCR Master Mix (Perkin-Elmer Applied Biosystems), $200 \mathrm{nM}$ forward and reverse primers and $100 \mathrm{nM}$ TaqMan probe. The TaqMan PCR conditions were: $95^{\circ} \mathrm{C}$ for 15 seconds followed by $60^{\circ} \mathrm{C}$ for one minute for 45 cycles in each case on OneStep real-time PCR (Perkin-Elmer Applied Biosystems). The amplification of the target gene mRNA relative to GAPDH was compared using the $\Delta \Delta \mathrm{Ct}$ method. The abundance of PR-A was calculated by subtracting the relative abundance of PR-B from that of total PR.

\begin{tabular}{ll}
$\begin{array}{l}\text { Table } 1 \text { Primers used for TaqMan real-time polymerase } \\
\text { chain reaction }\end{array}$ \\
\hline Gene & Primer \\
\hline PR-B & $5^{\prime}$-CTGGCCTATCCTGCCTGCCTCA-3' \\
& $5^{\prime}$-TGTCCAAGACACTGTCCAGCAG-3' \\
total PR & $5^{\prime}$ CGTGCCTATCCTGCCTCTA-3 \\
& $5^{\prime}$ CCGCCGTCGTAACTTTCGT-3' \\
ERa & $5^{\prime}$-GGGAAGCTACTGTTGCTCCTAAC-3' \\
& $5^{\prime}$-CACCATGCCCTTACACATTC-3' \\
ERß & $5^{\prime}$-GATCGCTAGAACACACCTTACCTGTA-3' \\
& $5^{\prime}$-GCGCAACGGTCCCACTA-3' \\
\hline
\end{tabular}

\section{Histology and immunohistochemistry}

All specimens fixed in 10\% paraformaldehyde solution were embedded in paraffin blocks. The sections were stained with hematoxylin and eosin for histological evaluation of the tissues. For deection of PR-A, a human PR-Aspecific mouse monoclonal antibody purchased from Novocastra (NCL-L-PGR-312; Vision BioSystems Inc., Norwell, MA) was used [36,37]. For PR-B immunostaining, mouse monoclonal antibody Ab-6 (NeoMarkers, Fremont, CA) was used [36,38]. For ER $\alpha$ and ER $\beta$ immunostaining, rabbit polyclonal antibodies (LS-B1470 and LS-B945, respectively, LifeSpan Biosciences, Seattle, WA, USA) were used. The antigen-antibody complexes were identified using the Universal DAKO LSAB2-labeled streptavidin-biotin peroxidase kit (Lifespan Biosciences).

\section{Statistics}

All experiments were performed in triplicate. The statistical calculations were performed using the StatView statistical software package (SAS Institute, Cary, NC), and the statistical significance of each difference was determined using the Kruskal-Wallis and MannWhitney $\mathrm{U}$ test or paired $t$-test as appropriate. A $P$ value of $<0.05$ was considered to be statistically significant.

\section{Results}

\section{Patient characteristics}

A total of 14 females who did not receive any medical treatment, 13 females who received dienogest and 16 females who received LA were evaluated in this study (Table 2). There were no relevant group differences in age or VAS at baseline. The use of concomitant medications recorded in patient-maintained diaries, including analgesic medications for endometriosis, did not differ relevantly between the groups at baseline.

At baseline, the mean \pm SD VAS score was $53.1 \pm 29.9$ $\mathrm{mm}$ in the endometriosis-control group, $46.2 \pm 22.6 \mathrm{~mm}$ in the endometriosis-dienogest group and $56.3 \pm 41.0$ $\mathrm{mm}$ in the LA group. Following surgical treatment, the mean VAS score decreased to $20.6 \pm 15.1 \mathrm{~mm}$ in the dienogest group and $21.1 \pm 18.0 \mathrm{~mm}$ in the LA group, demonstrating the non-inferiority of dienogest versus LA as measured by observed VAS score changes. At baseline, the mean \pm SD serum CA125 level was $60.3 \pm$ $34.1 \mathrm{U} / \mathrm{ml}$ in the endometriosis-control group, $60.6 \pm$ $35.8 \mathrm{U} / \mathrm{ml}$ in the endometiosis-dienogest group and $52.9 \pm 42.8 \mathrm{U} / \mathrm{ml}$ in the LA group. Following surgical treatment, the mean serum CA125 level significantly decreased to $34.8 \pm 14.9 \mathrm{U} / \mathrm{ml}$ in the dienogest group and to $34.9 \pm 20.8 \mathrm{U} / \mathrm{ml}$ in the LA group.

\section{PR isoform expression and PR-B/PR-a ratios in eutopic and ectopic endometrium}

Previous studies have demonstrated that the expression of repressive PR-A and the apparent downregulation of 
Table 2 Baseline patient characteristics

\begin{tabular}{|c|c|c|c|c|c|c|}
\hline & \multirow{3}{*}{$\begin{array}{l}\text { Patients } \\
\text { with } \\
\text { uterine } \\
\text { fibroids } \\
\text { ( } n=17) \\
\text { baseline }\end{array}$} & \multicolumn{5}{|c|}{ Endometriosis } \\
\hline & & \multirow{2}{*}{$\begin{array}{l}\text { Control }(n=14) \\
\text { baseline }\end{array}$} & \multicolumn{2}{|c|}{ Dienogest $2 \mathrm{mg}(\mathrm{n}=13)$} & \multicolumn{2}{|c|}{ LA $3.75 \mathrm{mg}(\mathrm{n}=16)$} \\
\hline & & & baseline & preoperation & baseline & preoperation \\
\hline Age (years, mean \pm SD & $44.2 \pm 6.8$ & $34.9 \pm 8.1$ & \multicolumn{2}{|c|}{$34.3 \pm 5.7$} & \multicolumn{2}{|c|}{$37.5 \pm 7.2$} \\
\hline Duration of drug administration & - & - & \multicolumn{2}{|c|}{$21.6 \pm 11.5$} & \multicolumn{2}{|c|}{$12.6 \pm 2.8$} \\
\hline Pelvic pain VAS (mm, mean \pm SD) & $23.8 \pm 18.2$ & $53.1 \pm 29.9$ & $46.2 \pm 22.6^{a}$ & $20.6 \pm 15.1^{b}$ & $56.3 \pm 41.0^{\mathrm{ab}}$ & $21.1 \pm 18.0^{b}$ \\
\hline CA-125 (U/ml, mean $\pm \mathrm{SD})$ & $33.1 \pm 20.4$ & $60.3 \pm 34.1$ & $60.6 \pm 35.8$ & $34.8 \pm 14.9^{c}$ & $52.9 \pm 42.8$ & $34.9 \pm 20.8$ \\
\hline \multicolumn{7}{|l|}{ r-AFS stage $(n, \%)$} \\
\hline I: minimal & $10(58 \%)$ & $0(0 \%)$ & \multicolumn{2}{|c|}{$0(0 \%)$} & \multicolumn{2}{|c|}{$0(0 \%)$} \\
\hline I: mild & $3(18 \%)$ & $0(0 \%)$ & \multicolumn{2}{|c|}{$0(0 \%)$} & \multicolumn{2}{|c|}{$2(13 \%)$} \\
\hline III: moderate & $4(24 \%)$ & $5(36 \%)$ & \multicolumn{2}{|c|}{$8(62 \%)$} & \multicolumn{2}{|c|}{$9(56 \%)$} \\
\hline IV: severe & $0(0 \%)$ & $9(64 \%)$ & \multicolumn{2}{|c|}{$5(38 \%)$} & \multicolumn{2}{|c|}{$5(31 \%)$} \\
\hline
\end{tabular}

LA, leuprolide acetate; VAS, visual analogue scale; r-AFS, revised American Fertility Society.

$\mathrm{SD}$, standard deviation.

A: $p<0.01$ compared to patients with uterine fibroids, $\mathrm{b}: p<0.01$ compared to endometriosis-control, c: $p<0.05$ compared to baseline.

stimulatory PR-B may explain the development of progesterone resistance in patients with endometriosis $[1,39]$. This study investigated whether treatment with dienogest or leuprolide acetate attenuates the expression of PR isoforms in ectopic endometrium.
The expression of PR-B (Figure 1A) was significantly dysregulated in control ectopic endometrial samples obtained from females who did not receive any treatment compared with that observed in the eutopic endometrium of patients with fibroids. In contrast, the endometrioma

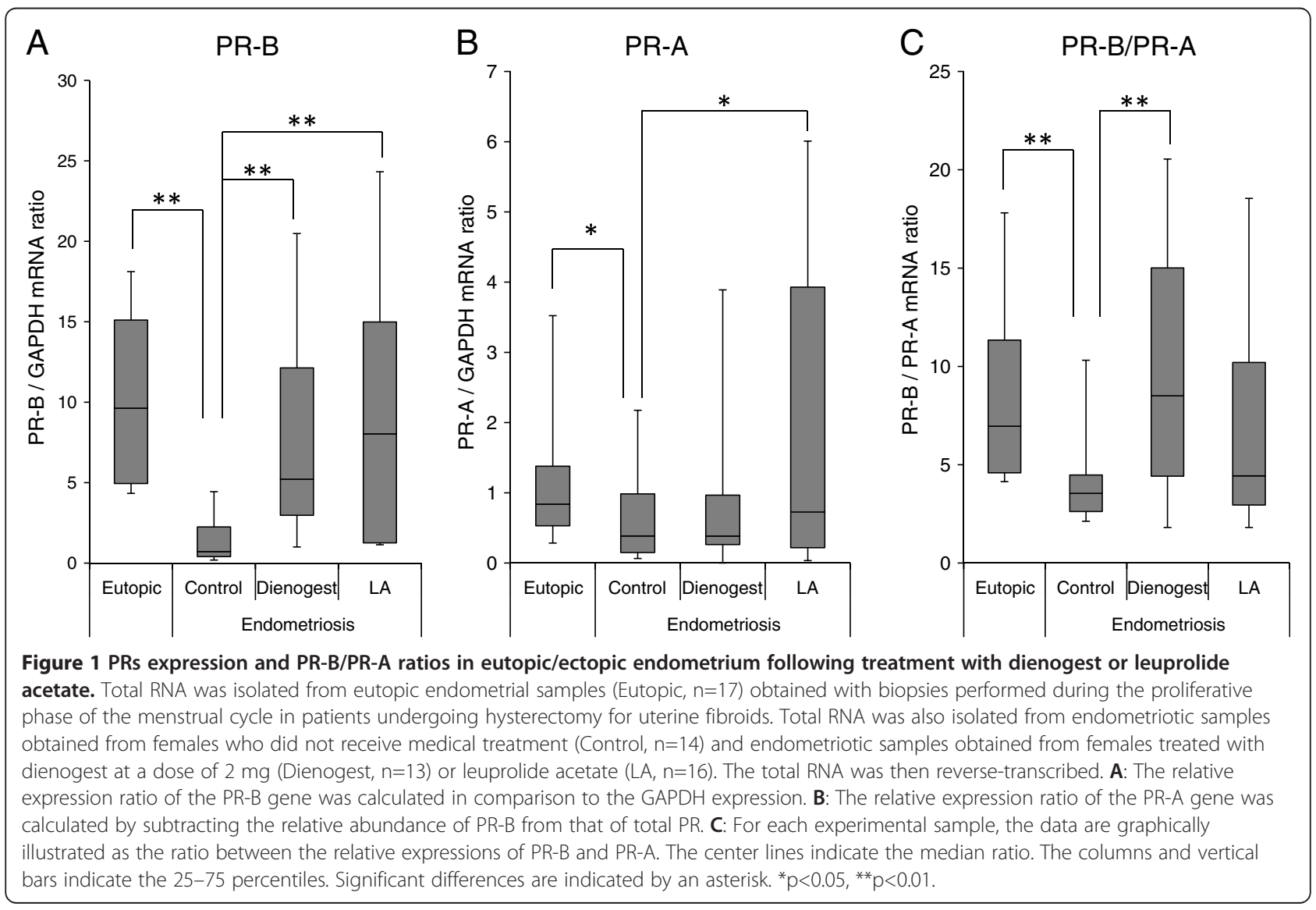


samples obtained from the patients who received dienogest or LA treatment showed a significantly greater expression of PR-B compared with that observed in the control tissues. The expression of PR-A (Figure 1B) was also significantly decreased in control ectopic endometrial samples compared with that observed in eutopic endometrium. Although the endometrioma samples obtained from the patients who received LA treatment showed a significantly greater expression of PR-A, dienogest treatment did not alter the expression of PR-A. Typical mRNA expression patterns of the PR isoforms are shown in the Additional file 1: Figure A, and explained in the Additional file 2. Progesterone resistance may be explained by the absence of PR-B and the dominant expression of PR-A $[20,21]$; therefore, we analyzed the PR-B/PR-A ratio at the mRNA level (Figure $1 C$ ). In the control ectopic endometrial samples, the $\mathrm{PR}-\mathrm{B} / \mathrm{PR}-\mathrm{A}$ ratio was significantly decreased compared with that observed in eutopic endometrium. Interestingly, dienogest treatment improved the PR-B/PR-A ratio; however, there were no significant differences in endometrioma after LA treatment.

\section{ER isoform expression and ER $\beta / E R a$ ratios in eutopic and ectopic endometrium}

This study investigated whether treatment with dienogest or leuprolide acetate attenuates the expression of ER isoforms in ectopic endometrium.

The expression of ER $\alpha$ (Figure 2A) was significantly dysregulated in the control ectopic endometrioma samples obtained from females who did not receive any treatment compared with that observed in the eutopic endometrium of patients with fibroids. In addition, the endometrioma samples obtained from the patients who received dienogest or LA treatment showed a significantly lower expression of $E R \alpha$ compared with that observed in eutopic endometrium. The expression of ER $\beta$ (Figure $2 \mathrm{~B}$ ) was also significantly elevated in the control ectopic endometrial samples compared with that observed in eutopic endometrium. Dienogest, but not LA, treatment altered the expression of ER $\beta$. Typical mRNA expression pattern of the ER isoforms are shown in the Additional file 1: Figure B, and explained in Additional file 2. A number of investigators have reported markedly elevated levels of ER $\beta$ and lower levels of ER $\alpha$ in human endometriotic tissues compared with that observed in eutopic endometrial tissues and cells $[16,22,23]$. Therefore, we also analyzed the ER $\beta / E R \alpha$ ratio at the mRNA level (Figure 2C). In the control ectopic endometrial samples, the ER $\beta / E R \alpha$ ratio was significantly increased compared with that observed in eutopic endometrium. Interestingly, dienogest treatment significantly improved the ER $\beta / E R \alpha$ ratio; however, there were no significant differences in endometrioma after LA treatment.

\section{Expression of PR and ER isoform proteins in the eutopic and ectopic endometriotic samples}

An immunohistochemical analysis revealed that PR-B immunoreactivity was strongly localized to the glandular epithelium and stromal cells in the eutopic endometrial
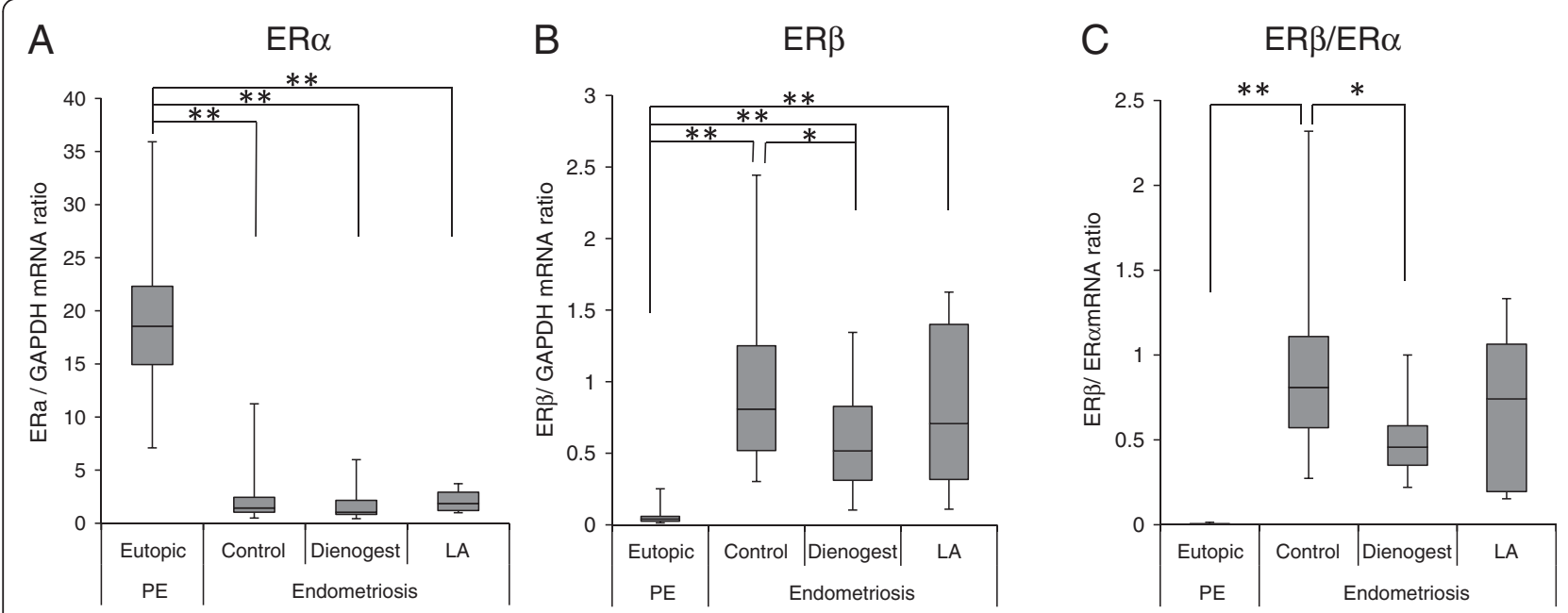

Figure 2 ERs expression and ERß/ERa ratios in eutopic/ectopic endometrium following treatment with dienogest or leuprolide acetate. Total RNA was isolated from eutopic endometrial samples (Eutopic, $n=17$ ) obtained with biopsies performed during the proliferative phase of the menstrual cycle in patients undergoing hysterectomy for uterine fibroids. Total RNA was also isolated from endometriotic samples obtained from females who did not receive medical treatment (Control, $n=14$ ) and endometriotic samples obtained from females treated with dienogest at a dose of $2 \mathrm{mg}$ (Dienogest, $n=13$ ) or leuprolide acetate $(L A, n=16)$. The total RNA was then reverse-transcribed. $\mathbf{A}$ : The relative expression ratio of the ERa gene was calculated in comparison to the GAPDH expression. $\mathbf{B}$ : The relative expression ratio of the ER $\beta$ gene was calculated in comparison to the GAPDH expression. C: For each experimental sample, the data are graphically illustrated as the ratio between the relative expressions of ERß and ERa. The center lines indicate the median ratio. The columns and vertical bars indicate the 25-75 percentiles. Significant differences are indicated by an asterisk. ${ }^{*} p<0.05,{ }^{* *} p<0.01$. 
samples during the proliferative phase (Figure 3E) and faintly localized to the glandular epithelium in the control ectopic endometrium (Figure 3F). In contrast, PR-A immunoreactivity appeared faintly in both the eutopic endometrial samples (Figure 3A) and the control ectopic endometrium (Figure 3B). After the patients were treated with dienogest or LA, immunostaining of PR-B increased in the ectopic endometrial epithelium (Figure 3G and H). $\mathrm{ER} \alpha$ was strongly localized to the glandular epithelium and stromal cells in the eutopic endometrium (Figure 3I) and faintly localized in the control ectopic endometrium (Figure 3J). Dienogest and LA treatment had no effect on the ER $\alpha$ expression (Figure $3 \mathrm{~K}$ and L). ER $\beta$ immunoreactivity appeared faintly in the eutopic endometrial samples (Figure $3 \mathrm{M}$ ). In contrast, ER $\beta$ was strongly localized to the epithelium and stromal cells in the ectopic endometrium (Figure $3 \mathrm{~N}$ ). Although dienogest treatment decreased the ER $\beta$ expression in ectopic endometrioma (Figure 3O), LA treatment seemed to have no effect on the ER $\beta$ expression (Figure 3P). No immunostaining was found in eutopic or ectopic endometrium when the primary antibodies were omitted (data not shown).

\section{Discussion}

The current study demonstrated statistically significant decreases in both PR-B and PR-A messenger RNA and proteins in ectopic endometrium derived from females with endometrioma who did not receive any medical treatment (Figure 1A, 1B, 3B, and 3F). Furthermore, the relative expressions of PR-B and PR-A were significantly lower in ectopic endometrium (Figure 1C). According to Attia et al. [20], the resistance of endometriotic tissue to progesterone, evident in both laboratory and clinical observations, can be explained by the absence of PR-B transcripts and proteins and the presence of PR-A in ectopic lesions. Similar findings have been reported in epithelial cells selected from a

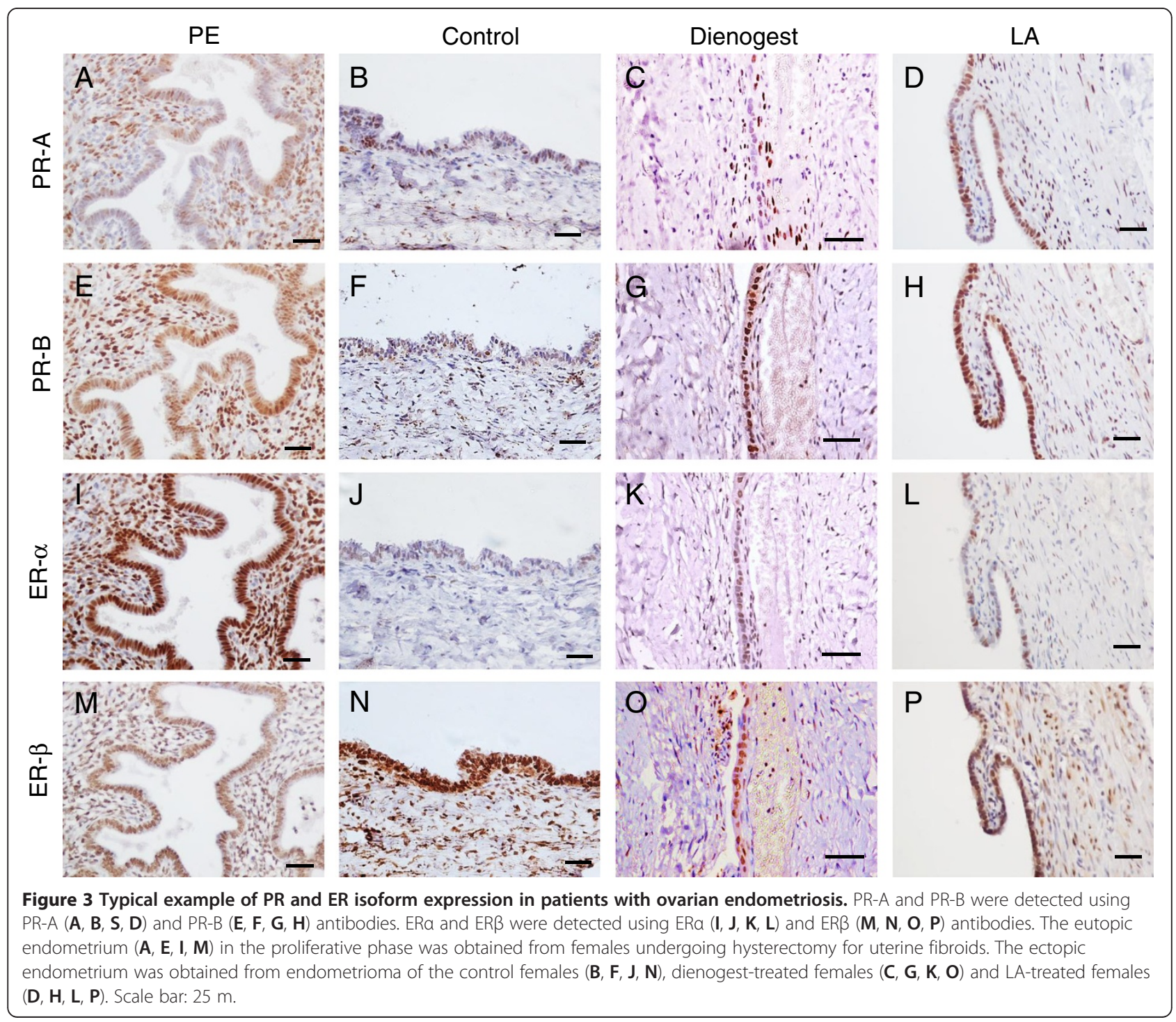


small number of ectopic samples [10]. Recently, independent investigators suggested that alterations in the relative expressions of PR-A and PR-B in endometrial cells may also play a pivotal role in the pathogenesis of endometriosis. A decreased PR-B/PR-A ratio has been demonstrated in ectopic tissue [5,10], and our findings are consistent with the results of these studies.

Several investigators have reported markedly higher levels of ER $\beta$ and lower levels of ER $\alpha$ in human endometriotic tissues and primary stromal cells compared with that observed in eutopic endometrial tissues and cells $[22,40]$. Recently, Bulun [41] reported that the levels of the nuclear receptors ER $\alpha, E R \beta$ and PR are quite different in endometriotic tissue and endometrium. The high ER $\beta /$ $\mathrm{ER} \alpha$ ratiosin endometriotic stromal cells in turn lead to increased ER $\beta$ binding to the PR promoter and mediate downregulation of the expression of PR [21]. ER $\beta$ acts as a suppressor of ER $\alpha$ in both endometrial and endometriotic stromal cells by binding to regulatory elements of specific promoters of the ER $\alpha$ and PR genes [42]. Therefore, ER $\alpha$ deficiency in endometriotic patients may be responsible for the failure of E2 to induce the PR expression, thus contributing to secondary PR deficiency and progesterone resistance in females with endometriosis. Although strikingly high quantities of E2 produced via local aromatase activity are observed in endometriotic tissue [43,44], the E2-dependent induction of PR is strongly inhibited [20]. Findings consistent with these studies were observed in the current study, which demonstrated statistically significant higher levels of ER $\beta$ and lower levels of ER $\alpha$ in ectopic endometrium derived from females with endometrioma (Figure 2 and Figure 3).

The endometrioma samples obtained from the patients who received dienogest or LA treatment showed a significantly higher expression of PR-B compared with that observed in the control endometrioma samples (Figure 1A and Figure 3). Although LA treatment increased the PR-A expression in the endometrioma samples, dienogest treatment did not alter the expression of PR-A (Figure 1B). Consequently, dienogest treatment improved the $\mathrm{PR}-\mathrm{B} / \mathrm{PR}-\mathrm{A}$ ratio; however, there were no significant differences in endometrioma after LA treatment (Figure 1C). Progesterone has recently been shown to reverse E2-stimulated increases in the ER $\beta$ mRNA and protein expression in cultured hippocampal slices [45]. Our current study demonstrates that dienogest treatment alters the expression of ER $\beta$ (Figure $2 \mathrm{~B}$ and Figure 3 ) and significantly decreases the $E R \beta / E R \alpha$ ratio in endometrioma (Figure $2 \mathrm{C}$ ). A recent report demonstrated that the promoter region of PR-B, but not PR-A, is hypermethylated in patients with endometriosis [21]. Although further studies are needed to clarify whether medical treatments might be associated with the methylation status of the PR-B promoter and to explore the mechanisms underlying the ER $\beta$ downregulation induced by dienogest, a decreased $E R \beta / E R \alpha$ ratio in the endometriotic tissues of patients treated with dienogest may be responsible for the observed improvements in the PR expressions.

\section{Conclusions}

We demonstrated that dienogest improves progesterone resistance in endometrial tissue. This finding enhances understanding of the anti-endometriotic effects of dienogest. It is possible that PR-B deficiency is only the tip of the iceberg with regard to the pathogenesis of endometriosis and that numerous other molecular aberrations may also contribute to the development of resistance to hormone treatments in females with endometriosis. Although our findings may explain at least part of the mechanisms underlying the clinical improvements observed in endometriotic patients using dienogest, the normalization of the PR expression profile observed in this study suggests that dienogest may be an effective and long-term treatment for endometriosis.

\section{Additional files}

Additional file 1: Typical mRNA expression patterns of the PR and

ER isoforms. A: A representative agarose gel showing amplicons of PR-B (upper panel), total-PR (middle panel), and $\beta$-actin (lower panel). B: A representative agarose gel showing amplicons of ERa (upper panel), ER $\beta$ (middle panel), and $\beta$-actin (lower panel).

Additional file 2: Supplemental Results.

\section{Competing interests}

The authors declare that they have no competing interests.

Authors' contributions

All authors read and approved the final manuscript.

\section{Acknowledgment}

We are grateful to Junko Hayashi and Kumiko Satoh for their secretarial assistance.

Received: 13 September 2012 Accepted: 29 October 2012

Published: 1 November 2012

\section{References}

1. Giudice LC, Kao LC: Endometriosis. Lancet 2004, 364:1789-1799.

2. Eskenazi B, Warner ML: Epidemiology of endometriosis. Obstet Gynecol Clin North Am 1997, 24:235-258.

3. Allen C, Hopewell S, Prentice A, Gregory D: Nonsteroidal anti-inflammatory drugs for pain in women with endometriosis. Cochrane Database Syst Rev 2009, 2:CD004753. doi:10.1002/14651858.

4. Brown J, Pan A, Hart RJ: Gonadotrophin-releasing hormone analogues for pain associated with endometriosis. Cochrane Database Syst Rev 2010, 12:CD008475

5. Sagsveen M, Farmer JE, Prentice A, Breeze A: Gonadotrophin-releasing hormone analogues for endometriosis: bone mineral density. Cochrane Database Syst Rev 2003, 4:CD001297.

6. Schindler AE: Non-contraceptive benefits of hormonal contraceptives. Minerva Ginecol 2010, 62:319-329.

7. Olive DL, Pritts EA: Treatment of endometriosis. N Engl J Med 2001, 345:266-275. 
8. Waller KG, Shaw RW: Gonadotropin-releasing hormone analogues for the treatment of endometriosis: long-term follow-up. Fertil Steril 1993, 59:511-515.

9. Vercellini P, Cortesi I, Crosignani PG: Progestins for symptomatic endometriosis: a critical analysis of the evidence. Fertil Steril 1997, 68:393-401.

10. Bulun SE, Cheng YH, Yin P, Imir G, Utsunomiya H, Attar $E$, Innes J, Julie Kim $\mathrm{J}$ : Progesterone resistance in endometriosis: link to failure to metabolize estradiol. Mol Cell Endocrinol 2006, 248:94-103.

11. Conneely OM, Maxwell BL, Toft DO, Schrader WT, O'Malley BW: The A and $B$ forms of the chicken progesterone receptor arise by alternate initiation of translation of a unique mRNA. Biochem Biophys Res Commun 1987, 149:493-501.

12. Kastner $P$, Bocquel MT, Turcotte B, Garnier JM, Horwitz KB, Chambon P, Gronemeyer $\mathrm{H}$ : Transient expression of human and chicken progesterone receptors does not support alternative translational initiation from a single mRNA as the mechanism generating two receptor isoforms. J Biol Chem 1990, 265:12163-12167.

13. Tora L, Gronemeyer H, Turcotte B, Gaub MP, Chambon P: The N-terminal region of the chicken progesterone receptor specifies target gene activation. Nature 1988, 333:185-188.

14. Tung L, Mohamed MK, Hoeffler JP, Takimoto GS, Horwitz KB: Antagonistoccupied human progesterone B-receptors activate transcription without binding to progesterone response elements and are dominantly inhibited by A-receptors. Mol Endocrinol 1993, 7:1256-1265.

15. Vegeto E, Shahbaz MM, Wen DX, Goldman ME, O'Malley BW, McDonnell DP: Human progesterone receptor A form is a cell- and promoter-specific repressor of human progesterone receptor B function. Mol Endocrinol 1993, 7:1244-1255.

16. Jackson KS, Brudney A, Hastings JM, Mavrogianis PA, Kim JJ, Fazleabas AT: The altered distribution of the steroid hormone receptors and the chaperone immunophilin FKBP52 in a baboon model of endometriosis is associated with progesterone resistance during the window of uterine receptivity. Reprod Sci 2007, 14:137-150

17. Burney RO, Talbi S, Hamilton AE, Vo KC, Nyegaard M, Nezhat CR, Lessey BA, Giudice LC: Gene expression analysis of endometrium reveals progesterone resistance and candidate susceptibility genes in women with endometriosis. Endocrinology 2007, 148:3814-3826.

18. Osteen KG, Bruner-Tran KL, Eisenberg E: Reduced progesterone action during endometrial maturation: a potential risk factor for the development of endometriosis. Fertil Steril 2005, 83:529-537.

19. Wardell SE, Edwards DP: Mechanisms controlling agonist and antagonist potential of selective progesterone receptor modulators (SPRMs). Semin Reprod Med 2005, 23:9-21.

20. Attia GR, Zeitoun K, Edwards D, Johns A, Carr BR, Bulun SE: Progesterone receptor isoform $A$ but not $B$ is expressed in endometriosis. $J$ Clin Endocrinol Metab 2000, 85:2897-2902.

21. Wu Y, Strawn E, Basir Z, Halverson G, Guo SW: Promoter hypermethylation of progesterone receptor isoform $\mathrm{B}$ (PR-B) in endometriosis. Epigenetics 2006, 1:106-111.

22. Brandenberger AW, Lebovic DI, Tee MK, Ryan IP, Tseng JF, Jaffe RB, Taylor $\mathrm{RN}$ : Oestrogen receptor (ER)-alpha and ER-beta isoforms in normal endometrial and endometriosis-derived stromal cells. Mol Hum Reprod 1999, 5:651-655.

23. Xue $Q$, Lin Z, Cheng YH, Huang CC, Marsh E, Yin P, Milad MP, Confino E, Reierstad S, Innes J, Bulun SE: Promoter methylation regulates estrogen receptor 2 in human endometrium and endometriosis. Biol Reprod 2007 77:681-687.

24. Trukhacheva E, Lin Z, Reierstad S, Cheng YH, Milad M, Bulun SE: Estrogen receptor (ER) beta regulates ERalpha expression in stromal cells derived from ovarian endometriosis. J Clin Endocrinol Metab 2009, 94:615-622.

25. Kohler G, Faustmann TA, Gerlinger C, Seitz C, Mueck AO: A dose-ranging study to determine the efficacy and safety of 1,2 , and $4 \mathrm{mg}$ of dienogest daily for endometriosis. Int J Gynaecol Obstet 2010, 108:21-25.

26. Strowitzki T, Faustmann T, Gerlinger C, Seitz C: Dienogest in the treatment of endometriosis-associated pelvic pain: a 12-week, randomized, doubleblind, placebo-controlled study. Eur J Obstet Gynecol Reprod Biol 2010, 151:193-198.

27. Cosson M, Querleu D, Donnez J, Madelenat P, Konincks P, Audebert A, Manhes $\mathrm{H}$ : Dienogest is as effective as triptorelin in the treatment of endometriosis after laparoscopic surgery: results of a prospective, multicenter, randomized study. Fertil Steril 2002, 77:684-692.

28. Strowitzki T, Marr J, Gerlinger C, Faustmann T, Seitz C: Dienogest is as effective as leuprolide acetate in treating the painful symptoms of endometriosis: a 24-week, randomized, multicentre, open-label trial. Hum Reprod 2010, 25:633-641.

29. Harada T, Momoeda M, Taketani Y, Aso T, Fukunaga M, Hagino H, Terakawa $\mathrm{N}$ : Dienogest is as effective as intranasal buserelin acetate for the relief of pain symptoms associated with endometriosis-a randomized, doubleblind, multicenter, controlled trial. Fertil Steril 2009, 91:675-681.

30. Petraglia F, Hornung D, Seitz C, Faustmann T, Gerlinger C, Luisi S, Lazzeri L Strowitzki T: Reduced pelvic pain in women with endometriosis: efficacy of long-term dienogest treatment. Arch Gynecol Obstet 2012, 285:167-173.

31. Okada H, Nakajima T, Yoshimura T, Yasuda K, Kanzaki H: The inhibitory effect of dienogest, a synthetic steroid, on the growth of human endometrial stromal cells in vitro. Mol Hum Reprod 2001, 7:341-347.

32. Fu L, Osuga Y, Morimoto C, Hirata T, Hirota Y, Yano T, Taketani Y: Dienogest inhibits BrdU uptake with G0/G1 arrest in cultured endometriotic stromal cells. Fertil Steril 2008, 89:1344-1347.

33. Shimizu Y, Mita S, Takeuchi T, Notsu T, Mizuguchi K, Kyo S: Dienogest, a synthetic progestin, inhibits prostaglandin E2 production and aromatase expression by human endometrial epithelial cells in a spheroid culture system. Steroids 2010, 76:60-67.

34. : Revised American Society for Reproductive Medicine classification of endometriosis: 1996. Fertil Steril 1997, 67:817-821

35. Karita M, Yamashita Y, Hayashi A, Yoshida Y, Hayashi M, Yamamoto H, Tanabe A, Terai $Y$, Ohmichi M: Does advanced-stage endometriosis affect the gene expression of estrogen and progesterone receptors in granulosa cells? Fertil Steril 2011, 95:889-894.

36. Mote PA, Johnston JF, Manninen T, Tuohimaa P, Clarke CL: Detection of progesterone receptor forms $A$ and $B$ by immunohistochemical analysis. J Clin Pathol 2001, 54:624-630.

37. Goldman S, Weiss A, Almalah I, Shalev E: Progesterone receptor expression in human decidua and fetal membranes before and after contractions: possible mechanism for functional progesterone withdrawal. Mol Hum Reprod 2005, 11:269-277.

38. Oh SY, Kim CJ, Park I, Romero R, Sohn YK, Moon KC, Yoon BH: Progesterone receptor isoform $(A / B)$ ratio of human fetal membranes increases during term parturition. Am J Obstet Gynecol 2005, 193:1156-1160.

39. Lessey BA, Metzger DA, Haney AF, McCarty KS Jr: Immunohistochemical analysis of estrogen and progesterone receptors in endometriosis: comparison with normal endometrium during the menstrual cycle and the effect of medical therapy. Fertil Steril 1989, 51:409-415.

40. Fujimoto J, Hirose R, Sakaguchi H, Tamaya T: Expression of oestrogen receptor-alpha and -beta in ovarian endometriomata. Mol Hum Reprod 1999, 5:742-747.

41. Bulun SE: Endometriosis. N Engl J Med 2009, 360:268-279.

42. Bulun SE, Cheng YH, Pavone ME, Xue Q, Attar E, Trukhacheva E, Tokunaga $H$, Utsunomiya $H$, Yin P, Luo X, et al: Estrogen receptor-beta, estrogen receptor-alpha, and progesterone resistance in endometriosis. Semin Reprod Med 2010, 28:36-43.

43. Zeitoun KM, Bulun SE: Aromatase: a key molecule in the pathophysiology of endometriosis and a therapeutic target. Fertil Steril 1999, 72:961-969.

44. Zeitoun K, Takayama K, Michael MD, Bulun SE: Stimulation of aromatase P450 promoter (II) activity in endometriosis and its inhibition in endometrium are regulated by competitive binding of steroidogenic factor-1 and chicken ovalbumin upstream promoter transcription factor to the same cis-acting element. Mol Endocrinol 1999, 13:239-253.

45. Aguirre C, Jayaraman A, Pike C, Baudry M: Progesterone inhibits estrogenmediated neuroprotection against excitotoxicity by down-regulating estrogen receptor-beta. J Neurochem 2010, 115:1277-1287.

doi:10.1186/1757-2215-5-31

Cite this article as: Hayashi et al:: Dienogest increases the progesterone receptor isoform $\mathrm{B} / \mathrm{A}$ ratio in patients with ovarian endometriosis. Journal of Ovarian Research 2012 5:31. 